\title{
Design of Drug Molecule Based Structure for Smad 3 Protein and Its Insilico Research of Leukemia Utilizing Bioinformatics Software
}

\author{
A. Manikandan, T. Jayalakshmi, P.B. Ramesh Babu
}

\begin{abstract}
The Research work on rational drug molecules design for Smad3,the conclusion is that out of all the inhibitors chosen for the docking, PTHrP emerged to be the best inhibitor for the protein Smad3.The precise reason for it was its docking energy which was the lowest (docked energy =-29.73), among all other inhibitors used. Hence the conclusion is that Smad3 is the best inhibitor, for Smad3. Hence the task was completed successfully. There are many reasons and factors responsible for induction of cancer. Leukemia is a type of cancer in blood or bone marrow and is characterized by an irregular proliferation of white blood cells.
\end{abstract}

\section{INTRODUCTION}

Drug molecules design is the methodology of discovering drugs by configuration, in view of their biological natural targets. Medications might be planned that dilemma to the dynamic district and repress this key atom. Anyway these medications would likewise must be planned in such a route as not to influence whatever other critical particles that might be comparative in appearance to the key atoms. The structure of the medication particle that can explicitly communicate with the biomolecules can be demonstrated utilizing computational devices. These apparatuses can enable a medication atom to be built inside the biomolecule utilizing information of its structure and the idea of its dynamic site.

Utilizing auxiliary data about medication targets or their regular ligands as a reason for the plan of successful medications. Medications work by interfacing with target atoms (receptors) in our bodies and modifying their exercises in a way that is useful to our wellbeing. At times, the impact of a medication is to animate the action of its objective while in different cases the medication obstructs the action of its objective. Proteins give a methods for transportation over a

cell film.

The at present acknowledged model for the cell layer is the liquid mosaic model. In this model, the film comprises of a Phospholipid bilayer. Outwardly of this bilayer are the

Revised Version Manuscript Received on July 18, 2019.

A. Manikandan, Assistant Professor, School of Bio-Engineering, Department of Genetic Engineering, Bharath University, Chennai, Tamil Nadu, India.

T. Jayalakshmi, Associate Professor, School of Bio-Engineering, Department of Genetic Engineering, Bharath University, Chennai, Tamil Nadu, India.

Dr. P.B. Ramesh Babu, Professor, School of Bio-Engineering, Department of Genetic Engineering, Bharath University, Chennai, Tamil Nadu, India. hydrophilic leaders of the phospholipid. The inside comprises of the hydrophobic tails of the phospholipid. Implanted all through the bilayer are proteins. These proteins are in charge of transporting certain substances over the layer just as perceiving mixes outside of the cell, which may influence the cells work.

The coupling site of a medication is 3-D fit as a fiddle. The medication must be molded to fit into explicit restricting destinations. The properties of a synthetic intensify that reason it to be organically dynamic are the properties of its structure, which is extremely mind boggling. Proteins for instance, overlap in unmistakable ways. On the off chance that the protein is collapsed in an alternate introduction, at that point it's capacity is modified significantly.

\section{Classes}

There are three classes of SMAD:

1) receptor directed SMAD (R-SMAD) which incorporate SMAD1, SMAD2, SMAD3, SMAD5 and SMAD9

2) the coSMAD SMAD4

3) inhibitory SMAD (I-SMAD) which incorporate SMAD6 and SMAD7

\section{MATERIALS AND METHOD}

\section{Retrieval of Protein Sequence of Smad3 in Homo sapiens}

Protein sequence of Smad3 in Homo sapiens was done from National Center of Biotechnology information (www.ncbi.nlm.nih.gov/). The sequence of protein was in FASTA format 


\section{DESIGN OF DRUG MOLECULE BASED STRUCTURE FOR SMAD 3 PROTEIN AND ITS INSILICO RESEARCH OF LEUKEMIA UTILIZING BIOINFORMATICS SOFTWARE}

>gi|18418623|gb|AAL68976.1| Smad3 [Homo sapiens] MSSILPFTPPIVKRLLGWKKGEQNGQEEKWCEKAV KSLVKKLKKTGQLDELEKAITTQNVNTKCITIPRS LDGRLQVSHRKGLPHVIYCRLWRWPDLHSHHELR AMELCEFAFNMKKDEVCVNPYHYQRVETPVLPPV LVPRHTEIPAEFPPLDDYSHSIPENTNFPAGIEPQSNI PETPPPGYLSEDGETSDHQMNHSMDAGSPNLSPN PMSPAHNNLDLQPVTYCEPAFWCSISYYELNQRVG ETFHASQPSMTVDGFTDPSNSERFCLGLLSNVNRN AAVELTRRHIGRGVRLYYIGGEVFAECLSDSAIFVQ SPNCNQRYGWHPATVCKIPPGCNLKIFNNQEFAA LLAQSVNQGFEAVYQLTRMCTIRMSFVKGWGAEY RRQTVTSTPCWIELHLNGPLQWLDKVLTQMGSPSI RCSSVS

\section{Homology Modeling}

Homology demonstrating is required when the accurate structure of the protein isn't accessible. The structure of Smad3 was likewise inaccessible, so homology displaying was required. It is otherwise called 'relative demonstrating'. Here we display the particle (protein) from amino corrosive arrangement by following a convention to show. The amino corrosive grouping is 'inquiry' or 'target' arrangement. Homology displaying methods rely upon distinguishing proof of at least one structures known as 'layout', which takes after the structure of inquiry succession. The grouping arrangement and format structure are utilized to deliver a basic model of the objective. Generally succession closeness compares to high auxiliary similitude.

Distinctive programming projects are utilized for Homology Modeling, for example,

1. CASP Protein Structure Prediction Center, Genome Center, Univ. California, Davis

\section{Swiss-Model Server (Free)}

3. CPH Models Server

4. Wloop The Loop Homology Modeling Server

5. What-If Server V.Friend's What-IF Homology Modeling Server

6. Composer Tripos Sybyl's Homology demonstrating devices. Likewise incorporates Matchmaker and GeneFold programming.

7. UCLA/DOE Server UCLA/DOE Fold Server

8. Predict Protein Server EMBL, Predict Protein Server

9. Abagyan Lab Server Scripps Research Institute

10. 3D-Jigsaw Comparative Modeling Server UK Site. Snap on accommodation to present the arrangement.

Recovery of inhibitor against Smad3

Inhibitor against Smad3 protein recovered through two noteworthy sources.

\section{BRENDA}

It (www.brenda.uni-koeln.de) is the principle accumulation of compound utilitarian information accessible to established researchers. BRENDA is kept up and created at the foundation of Biochemistry at the University of Cologne.

\section{NCBI Pubchem Compound}

PubChem Structure Search permits PubChem Compound Database to be questioned utilizing a concoction structure. Synthetic structure questions might be outlined utilizing the PubChem Sketcher. You may likewise indicate the auxiliary inquiry contribution by PubChem Compound Identifier (CID), SMILES, and SMARTS, Inch I, Molecular Formula, or by transfer of an upheld structure document position.

\section{Building of $3 d$ structure (PDB file) of Inhibitors}

3D structure of potent inhibitors are obtained by submitting the inhibitor name to the NCBI's Pubchem compound database and save the file in SDF format then converted it into PDB format by using Molecular format converter

Interface of Babel Molecular format converter for converting SDF format to PDB format:

\section{Babel Molecule format Converter:}

Babel is a cross-platform program designed to interconvert between many file formats used in molecular modeling and computational chemistry and related areas. Babel is a chemical toolbox designed to allowing anyone,convert, analyze, or store data from molecular modeling, chemistry, solid-state materials, biochemistry, or related areas.

Procedure to convert the for converting SDF format to PDB format

- First of all open the Babel page.

- Set the parameter for input and output file i.e. SDF for input file \& PDB for output file.

- Paste the data of 3D file in the input section or upload the SDF file.

- $\quad$ Click on the convert file.

The result will show in the output section in the form of PDB file, copy that data and paste in the word pad and save that file with (.pdb) extension.

\section{AUTODOCK}

In additions to using them for docking, the atomic affinity grids can be visualized. This can help, for example, to guide organic synthetic chemists design better binders.

$$
\begin{array}{cl}
\circ & \text { Autogrid } \\
\circ & \text { Autodock }
\end{array}
$$

\section{Docking Of Flexible Ligands to the Receptors}

For docking the flexible ligands to the receptors following software's can be used which are listed below: 


\begin{tabular}{|l|l|l|l|l|}
\hline SNo & Name & License Term & Platform & Kayword \\
\hline 1 & Auto dock & Commercial & UNIX,LINUX,SGI & GALGA,MC \\
\hline 2 & Affinity & Commercial & SGI & Monte Carlo method \\
\hline 3 & Dock Vision & Commercial & LINUX.IRIS & MC,GA \\
\hline 4 & $\begin{array}{l}\text { DOT(Duughter of } \\
\text { Turnip) }\end{array}$ & Free & Supercomputers, UNIX & \\
\hline 5 & Flex X & Commercial & UNIX & Fragments Based \\
\hline 6 & Shape & E-mail request & UNIX & $\begin{array}{l}\text { Structure and } \\
\text { chemistry of molecular } \\
\text { surface }\end{array}$ \\
\hline 7 & LEAPFROG & Commercial & SGI & ligand design \\
\hline 8 & Q site & Commercial & UNIX,IINUX,SGI & $\begin{array}{l}\text { Mired quantum and } \\
\text { molecular mechanics }\end{array}$ \\
\hline 9 & HINT & Commercial & Windows & Hydropathic interaction \\
\hline 10 & GOLD & Free evaluation & UNIX & GA \\
\hline
\end{tabular}

\section{PMV (Python Molecular Viewer)}

Python Molecular Viewer is a tool to view the binding of hydrogen bonds in the target molecule. It helps to visualize and analyze the hydrogen bonds.

\section{RESULTS AND DISCUSSION}

Retrieval of protein sequence of Smad3 protein;

>gi|18418623|gb|AAL68976.1| Smad3 [Homo sapiens] MSSILPFTPPIVKRLLGWKKGEQNGQEEKWCEKAV KSLVKKLKKTGQLDELEKAITTQNVNTKCITIPRS

LDGRLQVSHRKGLPHVIYCRLWRWPDLHSHHELR AMELCEFAFNMKKDEVCVNPYHYQRVETPVLPPVLV PRHTEIPAEFPPLDDYSHSIPENTNFPAGIEPQSNIPE TPPPGYLSEDGETSDHQMNHSMDAGSPNLSPN

PMSPAHNNLDLQPVTYCEPAFWCSISYYELNQRVG ETFHASQPSMTVDGFTDPSNSERFCLGLLSNVNRN

AAVELTRRHIGRGVRLYYIGGEVFAECLSDSAIFVQ SPNCNQRYGWHPATVCKIPPGCNLKIFNNQEFAA

LLAQSVNQGFEAVYQLTRMCTIRMSFVKGWGAEY RRQTVTSTPCWIELHLNGPLQWLDKVLTQMGSPSIR CSSVS

\section{Model by MODELLER}

\section{In Swiss PDB viewer}

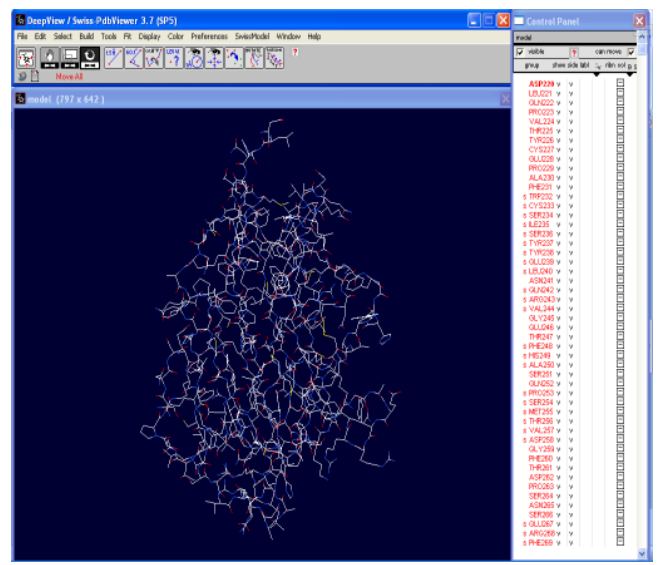

\section{In Rasmol}

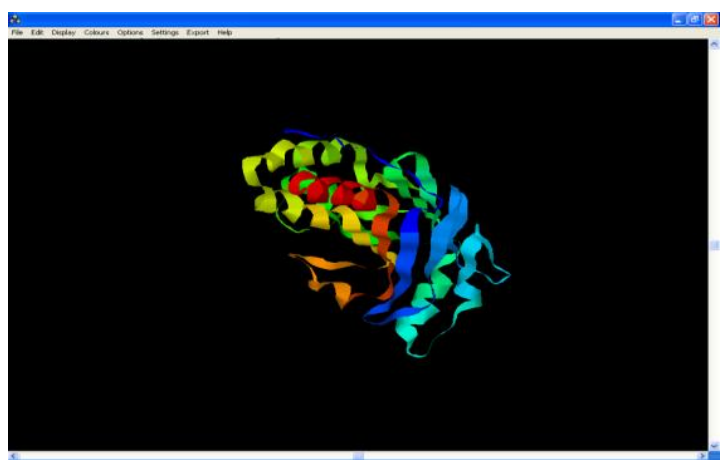

List of inhibitors against Smad3

(1). PD98059 CID: 4713 (2). SIS3 CID: 16079005 (3). SREBP-2 CID: 5469647 (4). STAT CID: $\underline{952079}$ (5). SB-202190

\section{CID: 5353940}

IUPAC name of different inhibitors, which show interaction with Smad3 protein. The IUPAC name of the inhibitor is further used in making pdb file of that inhibitor.

Docking of ligand to receptor

\section{AUTODOCK RESULTS}

Table shows Docked energies and other parameters of the inhibitors using Auto Dock docking program.

\begin{tabular}{|l|l|l|l|l|l|l|}
\hline $\begin{array}{l}\text { Sl.n } \\
0\end{array}$ & $\begin{array}{l}\text { Inhibitor } \\
\text { Name }\end{array}$ & $\begin{array}{l}\text { Docked } \\
\text { Energy }\end{array}$ & $\begin{array}{l}\text { Ref } \\
\text { RMS }\end{array}$ & $\begin{array}{l}\text { Free } \\
\text { Enegy }\end{array}$ & $\begin{array}{l}\text { Intermolecular } \\
\text { Energy }\end{array}$ & $\begin{array}{l}\text { Internal } \\
\text { Energy }\end{array}$ \\
\hline 1 & PD98059 & -7.45 & 79.25 & -8.52 & -9.14 & 1.69 \\
\hline 2 & SIS3 & -11.12 & 77.19 & -11.44 & -12.06 & 0.95 \\
\hline 3 & SREBP-2 & -8.31 & 97.65 & -6.44 & -8.31 & 0.0 \\
\hline
\end{tabular}

Table shows the results displayed by Autodock docking program displaying Free energy, Intermolecular-energy, Internal energy and finally Docked energy of the Smad3 with its inhibitor. Autodock docking results show that PTHrP inhibitor of Smad3 shows best interaction with the Smad3 with its docked energy of -29.73 .

Python Molecular Viewer (PMV) Results

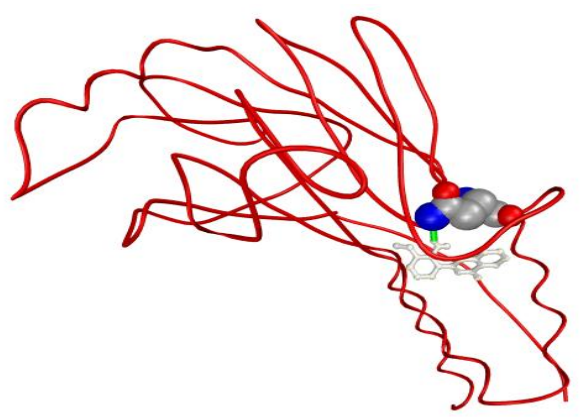

Fig 1: Hydrogen Bond Formed Between Protein's Active Site and Inhibitor PD98059 


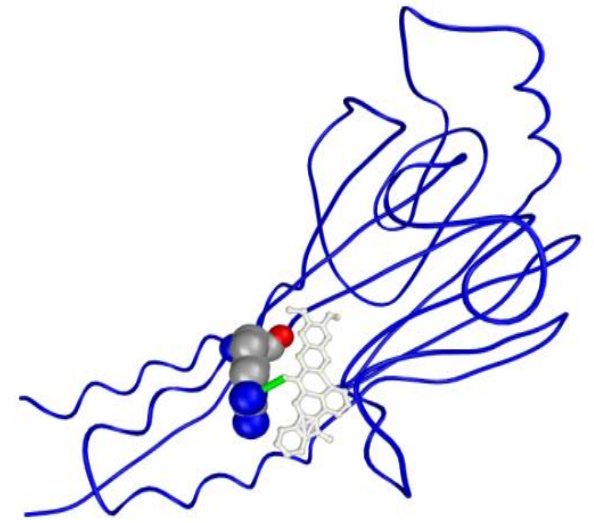

Fig 2: Hydrogen Bond Formed Between Protein's Active Site and Inhibitor SIS3

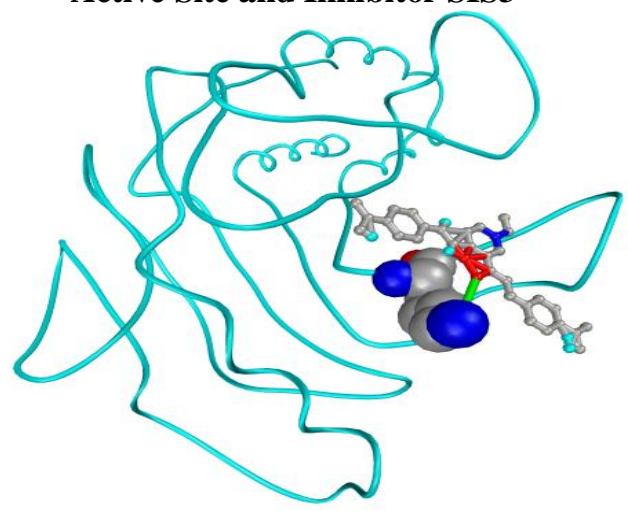

Fig 3: Hydrogen Bond Formed Between Protein's Active Site and Inhibitor SREBP-2

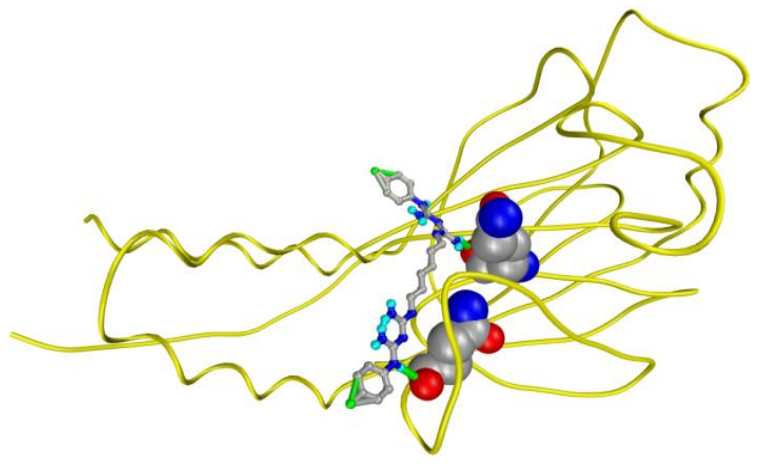

Fig 4: Hydrogen Bond Formed Between Protein's Active Site and Inhibitor STA

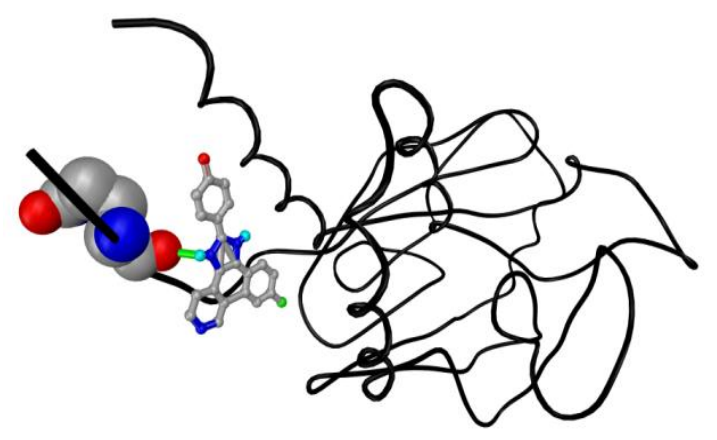

Fig 5: Hydrogen Bond Formed Between Protein's Active Site and Inhibitor SB-202190

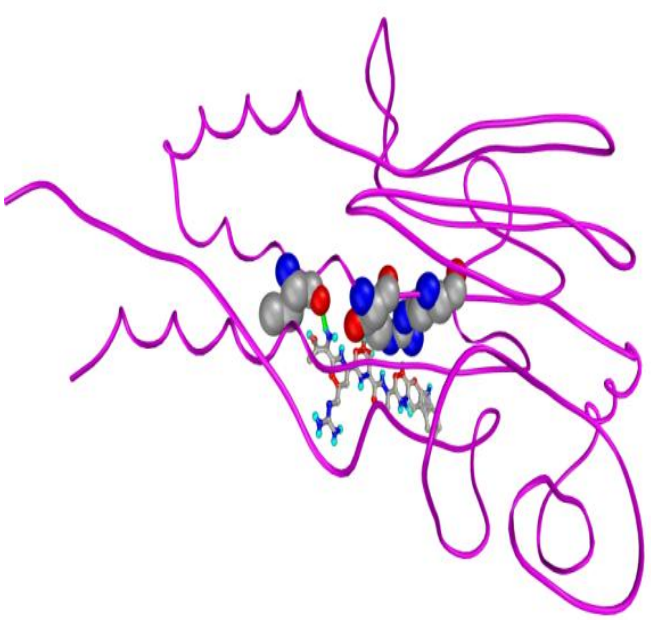

Fig 6: Hydrogen Bond Formed Between Protein's Active Site and Inhibitor PTHrP

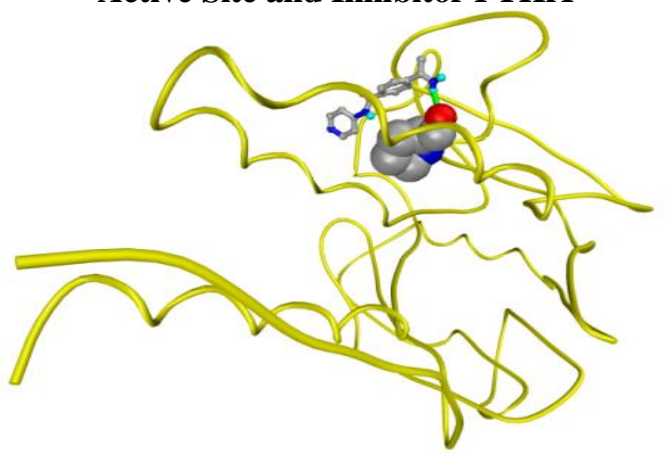

Rational Drug Designing Strategies reduce a lot of time, money and energy as compared to other hit and trial methods. According to recent trends mathematical modelling has become very valuable. The use of sophisticated software's and tools greatly help in this process, helping further development in research and development in this field. The main concern in AutoDock is computation of docking energy, which essentially should be less than zero. The more negative the docking energy, the better it is.

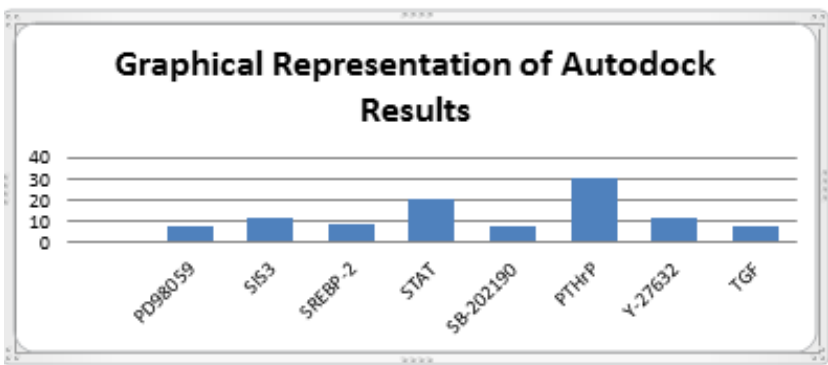

Fig. Shows the relative docked energies of various inhibitors with the target protein. from the Figure we can conclude that 'PTHrP' has the minimum docked energy, hence the best inhibitor.

\section{CONCLUSION}

However there is no inhibitor which is fully perfect and 
without any side effects. Nevertheless we try to reduce the burden on the general health of the patient to the maximum extent possible. Hence, newer drugs are required which have the same efficacy as the older one but are having fewer side effects. The initial phase of discovering a new drug nowadays is by using CADD. This method has greatly reduced the time, energy and money involved in the traditional methods. After a drug has been designated in-silicosis further verification is done, as stated earlier in laboratories. This method of using computer to design the drugs has indeed hastened the process of drug discovery.

Smad3 is a player in a phone organize hand-off framework called the changing development factor B (TGF-B) flagging course. TGF-B ties to receptors on the outside of platelets that create in bone marrow and enacts a multi-protein course that transfers these outer signs into the core of the cell. These signs regularly moderate the rate at which these platelets multiply. At the point when this flag pathway is interfered with, TGF-B can never again control cell expansion, and this can prompt leukemia. Loss of the Smad3 protein is a key occasion in youth T-cell leukemia. The quality for Smad3 is on chromosome 15 in locale $15 q 21-q 22$.

In mice, cancellation of one or the two duplicates of the Smad3 quality explicitly impedes the capacity of TGF-B to stop T-cell multiplication, so the disclosure that Smad3 was novel to the T-cell leukemia was not astounding. The shock and puzzle - of these discoveries is the science behind Smad3's nonattendance. The leukemia cells created ordinary dimensions of Smad3 mRNA - the guidelines that cells use to make protein - demonstrating that the Smad3 quality is turned on. Besides, the scientists found that the arrangement of the Smad3 quality in patient examples was indistinguishable to the typical Smad3 quality found in solid T cells, connoting that a hereditary transformation was not the offender either.

Rational Drug Designing Strategies reduce a lot of time, money and energy as compared to other hit and trial methods. According to recent trends mathematical modelling has become very valuable recently. The use of sophisticated software's and tools greatly help in this process, helping further development in research and development in this field.

Through my Endeavour I came to the conclusion that selective inhibitors are the best suited for inhibiting the action of Smad3.The dock energy table and the docked energy graph indeed confirm it. The PMV showed us the sites where the inhibitor attacks the target protein. It also shows the hydrogen bonds formed between proteins active site and the inhibitor.

The result can act as a guideline for the carrying of further experimentation to be carried out in wet lab (i.e. laboratories) for the further verification of the inhibitor.

Hence we saw how rational drug design strategies reduce time, energy and money involved in drug discovery. The complexity of the protein plays a key role in designing of the drug, simpler the drug more easily the molecule will be docked with the inhibitor

\section{REFERENCES}

1. Greer J., Erickson J.W., Baldwin J.J. and Varney M.D. (1994). Application of the three-dimensional structures of protein target molecules in structure-based drug design. $\mathrm{J}$ Med Chem 37 (8): 1035 - 1054.

2. Gubernator K, Böhm HJ (1998). Structure-Based Ligand Design, Methods and Principles in Medicinal Chemistry. Weinheim: Wiley-VCH.

3. I.D. Kuntz, "Structure-based Strategies for Drug Design and Discovery," Science, 257:1078-1082, 1992.

4. P. Charifson and I.D. Kuntz, "Recent Successes and Continuing Limitations in Computer-Aided Drug Design," in: Practical Application of Computer-Aided Drug Design, P. Charifson, ed., pp. 1-37, Marcel-Dekker, New York, 1997.

5. Griffith, J. et al. The structural basis for autoinhibition of FLT3 by the juxtamembrane domain. Molecular Cell 13, 169-178 (January 30, 2004).

6. Dessen P, Knuutila S, Huret JL Chromosome 1. Atlas Genet Cytogenet Oncol Haematol. 2002.URL: http://AtlasGeneticsOncology.org/Indexbychrom/idxa_1. html

7. The relation between the divergence of sequence and structure in proteins. Chothia, C., Lesk, A.M., EMBO J., 5 (1986) 823-836.

8. Sander, C., Schneider Database of homology-derived protein structures and the structural meaning of sequence alignment, R., PROTEINS, 9 (1991) 56-68.

9. Swindells, M.B., Thornton, J.M., Modelling by homology. Curr.Op.Struct.Biol, 1 (1991) 219-223.

10. Hilbert, M., B G., Jaenicke, R., Structural relationships of homologous proteins as a fundamental principle in homology modeling. PROTEINS, (1993), 17, 138-151.

11. Lesk, A.M., Chothia, C., J.Mol.Biol.,How different amino acid sequences determine similar protein structures: the structure and evolutionary dynamics of the globins. (1980) 136, 225-270.

12. Kabsch, W., Sander, C., On the use of sequence homologies to predict protein structure: identical pentapeptides can have completely different conformations. PNAS, (1984) 81, 1075-1078.

13. Plastocyanin and Azurin. Chothia, C., Lesk, .M., Evolution of proteins formed by b-sheets. J.Mol.Biol, (1982) 160, 309-323.

14. Bajorath, J., Stenkamp, R., Aruffo, A.Knowledge-based model building of proteins: concepts and examples., Prot.Sci, (1993) 2, 1798-1810.

15. Lesk, A.M., Boswell, .R., Homology modelling: inferences from tables of aligned sequences. Cur.Op.Struc.Biol. (1992) 2, 242-247.

16. Havel, T.F., Snow, M.E., A new method for building protein conformations from sequence alignments with omologues of known structure. J.Mol.Biol., (1991) 217 $1-7$.

17. Reid, L.S., Thornton, J.M., Rebuilding flavodoxin from Ca coordinates: a test study. PROTEINS, (1989) 5, 170-182.

18. Greer, J.Comparative modeling of homologous proteins., Meth.Enzym., (1991) 202, 239-252.

19. Sudarsanam, S., March, C.J., Srinivasan, S.,Homology modeling of divergent proteins. J.Mol.Biol., (1994) 241, 143-149.

20. Lee, R.H.,Protein model building using structural homology. Nature, (1992) 356, 543-544.

21. Sali, A., Blundell, T.L., Comparative modelling by satisfaction of spatial restraints. (1993) 234, 779-815.

22. Summers, N.L., Karplus, M.,Modelling of globular proteins. A distance based search procedure for the construction of insertion regions and non-pro mutations. J.Mol.Biol, (1990) 216,991-1016. 
23. Schiffer, C.A., Caldwell, J.W., Kollmann, P.A., Stroud, R.M.,Prediction of homologous protein structures based on conformational searches and energetics. PROTEINS, (1990) 8, 30-43.

24. Swindells, M.B., Thornton, J.M.,Modelling by homology. Curr,Op.Struc.Biol., (1991) 1, 19-223.

25. Moult, J., Pedersen, J.T., Judson, R., Fidelis, K., A large-scale experiment to assess protein structure prediction methods. PROTEINS, (1995) 23, 2-4.

26. Mosimann, S., Meleshko, R., James, N.G.A critical assessment of comparative molecular modeling of tertiary structures of proteins., PROTEINS, (1995) 23, 301-317.

27. Harrison, R.W., Chatterjee, D., Weber, I.T.,Analysis of six protein structures predicted by comparative modelling techniques. Proteins, (1995) 23, 463 